\section{The accuracy of dietary advice provided to rabbit owners calling UK veterinary practices}

\section{Ruby Stevens ${ }^{1}$, Alison Lambert ${ }^{2}$, Sophie Dainty ${ }^{2}$, Kate Cobb ${ }^{1}$, Liz Mossop ${ }^{1}$}

1 University of Nottingham - School of Veterinary Medicine and Science, Leicestershire, UK

2 Onswitch Ltd, Lincolnshire, UK

\section{OBJECTIVES}

To assess the accuracy of information given in response to rabbit related telephone enquiries.

\section{METHODS}

1,362 telephone calls were made to practices across the UK in October 2015 (519 corporate, 843 independent), asking about rabbit vaccinations. Half the callers also asked whether pellets were the best food for rabbits.

\section{RESULTS}

$4.9 \%$ of vaccination query only calls mentioned diet without being prompted, with corporate practices being statistically significantly more likely to discuss diet than independent ones. In the diet query calls, fourteen different combinations of food were recommended, with the most common being pellets alone, (the PDSA recommends an optimum diet featuring just $2-3 \%$ pellets). Only $19 \%$ of practices that discussed diet made a recommendation for the optimum diet.

\section{IMPACT/CLINICAL SIGNIFICANCE}

As the third most popular pet in the UK, veterinary practices should be able to provide accurate advice about rabbits, particularly regarding diet. The first owner contact is not only a fantastic opportunity for a practice to gain a new client, but also to give optimum disease prevention advice, maximising rabbit welfare. It is therefore concerning that receptionists are not giving accurate advice, and further training is required.

\section{FUNDING/DECLARATIONS OF INTEREST}

This research was undertaken by a student of Veterinary Medicine and Science at the University of Nottingham with Onswitch. 